\title{
ПОСЛЕДСТВИЯ СЕМАНТИЧЕСКИХ ИЗМЕНЕНИЙ
}

\section{CLASSIFICATION AND PECULIARITIES OF SEMANTIC CHANGES}

\section{S. Aleshkevich}

Summary: A new name is required to designate a new object or idea, three options are possible: to form a new word from existing elements; borrow a term from a foreign language or other source; finally, change the meaning of the old word. Thus, the need to find a new name is an extremely important reason for semantic changes. The speed of scientific and technological progress in the world makes ever higher demands on linguistic resources, the possibility of metaphor and other types of semantic changes are used on a scale. Of all the linguistic techniques available, changing of meaning is the simplest, most discreet, and perhaps the most elegant way to keep pace with the progress of civilization.

Keywords: range of meaning, specialisation, pejorative development, meliorative development, linguistic resources, associations theory, similarity, naming, differentiation of synonyms, semantic changes, semantic law.

\author{
Алешкевич Сергей Сергеевич \\ к.филол.н., дочент, Белгородский университет \\ кооперации, экономики и права \\ aleshkevichss@mail.ru
}

Аннотация: Новое имя требуется для обозначения нового объекта или идеи, возможны три варианта: сформировать новое слово из существующих элементов; заимствовать термин из иностранного языка или другого источника; наконец, изменить значение старого слова. Таким образом, необходимость найти новое имя является чрезвычайно важной причиной семантических изменений. Скорость научно-технического прогресса в мире предъявляет все более высокие требования к лингвистическим ресурсам, а возможности метафоры и других типов семантических изменений используются в полной мере. Из всех доступных лингвистических приемов изменение значения самый простой, самый осторожный и, возможно, самый элегантный способ идти в ногу с прогрессом цивилизации.

Ключевые слова: объем понятия, специализация значения, уничижительное развитие, мелиоративное развитие, лингвистические ресурсы, ассоциативная теория, сходство, именование, дифференциация синонимов, семантические изменения, семантический закон.

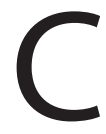

реди многочисленных последствий, которые могут возникнуть в результате семантических изменений, особое внимание следует уделить двум проблемам: объему понятия и эмоциональному подтексту нового значения по сравнению со старым.

\section{1. Изменение объема понятия: расширение и сухкение значения}

Во многих ранних исследованиях по семантике, авторы разделяли значения на три основные категории: расширение, сужение, а также разнообразную третью группу, которая не показала ни расширения, ни сужения объема понятия. Эта, так называемая «логическая классификация», будучи простой и простой в использовании, имела некоторые серьезные недостатки. Она основывалась на единственном формальном критерии и не объясняла ни окончательные причины изменений, ни его психологический фон. Другим недостатком было то, что все три категории были неоднородными: под заголовками «расширение» и «сужение» возникло множество изменений, которые не имели ничего общего, кроме малозначительного факта о том, что новый смысл был шире или уже старого; все, что не соответствовало этому критерию, было в итоге помещено в эту разноликую группу.

Факт остается фактом, что многие слова по разным причинам расширили или сузили свое значение и эта тенденция продолжается. Некоторые термины практи- чески удвоили или вдвое сократили свой объем понятия. Английское слово uncle («дядя»), например, происходит от французского, и в свою очередь, от латинского слова avunculus, которое означало лишь один вид дяди, а именно, брата матери, тогда как брата отца называли patruus. Так как последнее слово вышло из употребления, потомки avunculus должны были остаться для обоих видов дяди, так что объем понятия латинского термина был удвоен. В большинстве случаев, однако, расширение и сужение значения меняли более радикально сферу использования конкретного слова.

(1) Сужение значения. Механизм действия можно продемонстрировать на простом примере. Английское слово voyage первоначально означало «путешествие», как и соответствующий французский термин. С течением времени его семантика сузилась, и данное слово начало означать «путешествие по морю или воде». Конечным результатом изменения было то, что слово теперь применимо к меньшему количеству реалий, но говорит нам больше о них; его сфера применения была ограничена, но его смысл пополнился дополнительной функцией: «путешествовать по воде». С точки зрения логики, его «расширение» уменьшилось, а «намерение» соответственно увеличилось.

Наиболее частой причиной сужения значения является специализация значения в рамках отдельной социальной группы, чаще всего это приводит к возникнове- 
нию топологии, но она также может навсегда сократить диапазон слова в целом. Другой причиной ограничения является эвфемизм, в том числе разнообразие, которое вызвано скорее иронией, чем табу. Известным примером является слово poison («яд»), которое исторически является тем же словом, что и potion («зелье»). Самый неприятный аспект смысла, тот факт, что зелье является «ядовитым», был оставлен недосказанным, но, когда слово стало тесно ассоциироваться с табулизированным значением, оно постепенно сузило свое значение до этого особого вида зелья и никакого другого.

Несколько названий животных были сужены от рода к виду или подвергались более резкому сужению значения. Deer («олень») когда-то имело значение «зверь», hound («гончая») означало «собака». Интересно отметить, что во всех трех случаях немецкие слова - das Tier, der Hund, der Vogel - остались в более широкой семантике.

Интересным примером сужение значения является английское слово corn («кукуруза»), которое в дополнение к своему общему значению «семя зерновых культур», начало обозначать наиболее важную зерновую культуру, производимую в определенном районе: пшеница в Англии, овес в Шотландии, кукуруза в Америке.

(2) Расширение значения. - Некоторые лингвисты предположили, что расширение является менее распространенным процессом, чем сужение, и это недавно было подтверждено экспериментами, проведенными психологом Хайнцем Вернером. По словам самого профессора Вернера, есть две основные причины этой тенденции: одной из них является то, что преобладающая тенденция развития направлена скорее на дифференциацию, а не на синтез. Вторая причина, связанная с первой, заключается в том, что формирование общих понятий из конкретных терминов имеет меньшее значение в ненаучном общении, хотя это скорее характерная черта научной деятельности. Другими словами, язык в повседневной жизни направлен на точное и конкретное, а не на абстрактное и общее.

Тем не менее случаи семантического расширения довольно часто встречаются в различных языках. С чисто логической точки зрения они являются полной противоположностью сужения: имеется увеличение в виде «расширения значения», слово применяется к более широкому разнообразию реалий; в то же время его «намерение» (или внутренняя форма) сократится, оно будет менее полно рассказывать нам о вещах, о которых идет речь. Таким образом, французское слово basket («корзина») происходит от латинского слова panarium («корзина для хлеба»), которое, в свою очередь, произошло от слова panis («хлеб»). Когда связь с понятием «хлеб» исчезла, это слово могло относиться уже к большему количеству объектов, чем ранее, но его значение несколько поблек- ло, поскольку оно утратило одну отличительную черту. Слово target, сокращенное от target shield, первоначально означало «легкий круглый щит или баклер», а также щитоподобную структуру, отмеченную концентрическими кругами, применяемые при стрельбе; теперь это слово имеет намного более широкий и, следовательно, менее специфичный объем значения.

Расширение значения, как и его сужение, часто обусловлено социальными факторами. Слово, переходящее из ограниченной среды в общедоступное использование, будет иногда расширять свое значение и терять некоторые свои отличительные черты в этом процессе. Часто цитируемым примером может служить французское слово arriver («прибытие»), в английском arrive; оба эти слова когда-то означали «прибывать к берегу», как и в латинском arripare, которое в свою очередь, произошло от слова: ripa («берег»). Из смежной сферы имеется современное слово rival («соперник»), которое по причине расширения значения, берущего начало во времена Римской Империи: латинское слово rivales («соперничество»), происходящее от rivus («ручей, маленький поток»), буквально означало «те, кто имеет или использует тот же самый ручей, или соседей»; позже «соперничество» распространилось на любовь и другие сферы жизни.

Другой причиной расширения является необходимость в «сложных словах» с чрезвычайно туманным и обобщенным значением. Латинское слово causa являлось точным и хорошо определенным термином, в то время, как его романские последователи: французcкoе chose, итальянское, а также испанское слово cosa («вещь»), сейчас рассматриваются в качестве одних из самых туманных слов в данных языках; Во французском словосочетании quelque chose, в действительности приобрело значение неопределенного местоимения, означающее «что-то, что-либо». Между тем, французcкое cause («дело»), а также итальянское и испанское causa («причина»), которые были заимствованы непосредственно из латыни, сохраняют свою первозданную точность. Слово machine («механизм») также стало во французском универсальным словом в значении «вещь, гаджет».

Среди слов, которые расширили свое значение, есть несколько названий животных и растений. Любопытный случай - это слово rose («роза») в некоторых южно-славянских языках его используют в общем значении слова «цветок». Это использование даже затронуло некоторые соседние немецкие и итальянские диалекты. В некоторых случаях, термин, который когда-то означал: «молодое животное» или «растение», приобрел значение всего вида: французское слово pigeon («голубь»), dindon («индюк») и hetre («бук») приобрели свои нынешние значения таким образом. 


\section{2. Изменения в ошенке: уничижительные и мелиоративные тенденшии}

Уничижительные тенденции настолько распространены в языке, что некоторые ранние семантисты расценили их как фундаментальную тенденцию, симптом «пессимистической полосы» в человеческом разуме.

Эвфемизм или псевдоэвфемизм является движущей силой многих уничижительных событий. Если эвфемистический заменитель перестает ощущаться как таковой, если он становится напрямую связанным с идеей, которую он был призван скрыть, это приводит к постоянному обесцениванию его значения. Именно этот фактор объясняет уничижение многих слов: disease («болезнь»), undertaker («предприниматель»), silly («глупый») и другие.

Вторым фактором, приводящим к уничижительным изменениям смысла, является влияние определенных ассоциаций. Разветвление семантики латинского слова captivus, может послужить хорошим примером. Исходя из идеи плена, это слово приобрело отрицательные значения на разных языках, хотя и не на всех: испанское cautivo по-прежнему означает «заключенный». Во французском это стало chetif («слабый, болезненный, бедный, несчастный»); связующим звеном была идея о человеке, который доминировал и ослаблялся своими страстями. Подобные ассоциации привели к другому результату в итальянском, где cattivo означает («плохой»). Еще одна линия развития находится в английском слове caitiff («презренный, трусливый»), англо-нормандского происхождения, которое сейчас является архаичным и поэтичным. Это развивалось через три стадии:

1. «пленник, заключенный»;

2. «кто-то в жалком положении»;

3. «подлый, жалкий, негодяй, злодей».

Подобным образом, ситуация повторилась и с некоторыми другими терминами в той же сфере: английское слово wretch («негодяй») когда-то означал «изгнание», хотя его значение сильно ухудшилось, соответствующее немецкое слово «Recke» возросло в оценке и теперь означает «воин, герой»

Третий источник уничижительных событий - человеческие предрассудки в разных формах. Ксенофобия, как уже отмечалось, наполнила некоторые иностранные слова уничижительным смыслом: немецкое слово Ross («боевой конь»), привнесло во французскую лексику слово rosse («глиняный кувшин»), а слово из средневекового голландского языка boeckin («маленькая книжечка») - французское слово bouquin («старая книга, бесполезная книга»), хотя в привычной речи этот термин теперь свободен от каких-либо нежелательных коннотаций. Португальское слово palavra приобрело в английском, внешнюю форму palaver («болтовня»). Эти же анти-иностранные традиции отражаются в странных превратностях некоторых этнических наименований. Английское слово slave («раб»), французское слово esclave («порабощенный») и т.д. - являются словами с тем же самым значением.

Социальные предрассудки в отношении определенных классов и профессий также исказили значение многих слов. Такие термины, как английское слово boor («хам»), а также французское слово rustre («хам»), происходящее от латинского rusticus, демонстрируют униженное положение крестьян того времени. Латинское слово villanus («житель фермы»), привнесло в английский язык исторический термин villein («крепостной»), а также уничижительный villain («злодей»), в то время как современный французский villain означает «ужасный, уродливый». Другие социальные группы стали жертвами подобных предрассудков. Первоначально слово brigand («разбойник») имело значение «легкомысленный, нерегулярный пехотинец», a knave («мошенник») когда-то означало «мальчик», и в особенности «мальчик, нанятый в качестве слуги». Французское слово coquin («жулик, негодяй») имело раннее значение beggar («нищий»), а faquin («хам»), приобрело значение «портье». Предрассудки высшей социальной иерархии, также не остались без внимания и предубеждения. Слово pedant («педант»), когда-то имело значение «педагог» или «школьный учитель», а взлеты и падения слова bourgeois («буржуазные») образовали бы интересную главу социальной истории. Этот класс стал предметом критики не только со стороны руководителей и подчиненных, но также художников и интеллектуалов.

В то время как существует большое количество слов, значение которых претерпело уничижение, другие слова изменились в противоположном направлении. Эта, так называемым «мелиоративная» тенденция, привлекла меньше внимания, по сравнению с уничижительной и в целом, объективно, она считается менее частотной. Они подразделяются на две категории. Первая включает в себя те случаи, когда улучшение является чисто отрицательным: «процесс постепенного ослабления, термин с неприятным значением потеряет большую часть своей стигмы и станет лишь слегка неблагоприятным». Пример ослабления значения английского слова past («вредитель»), которая когда-то означала «мор» и, в особенности, «бубонную чуму». Слово plague («чума») имело подобное развитие.

В гиперболических выражениях такое ослабление может полностью отменять неприятное значение слова. Это же произошло, с целым рядом английских прилагательных: awful («ужасный»), dreadful («отвратительный»), frightful («страшный») и многими другими. Более продвинутая стадия данной тенденции может просматриваться в значении немецкого слова sehr («очень»), которое эти- 
мологически является тем же словом, что и английское sore («больной»).

Существуют также различные случаи положительного улучшения значения. Это может быть простой ассоциацией идей. Прилагательное nice («милый»), происходит посредством старо-французского языка от латинского слова nescius («невежественный») и во времена Шекспира оно имело несколько «не достойных» значений: оно могло означать wanton («бессмысленный»), lascivious («сладострастный»).

Постепенно значение слова менялось посредством таких значений как fastidious («привередливый») и delicate («нежный») в мелиоративном направлении; начиная со второй половины восемнадцатого века, оно имеет смысл «приятный, восхитительный», а с начала девятнадцатого - «добрый, внимательный, приятный для других».

Другие виды мелиоративного развития происходят благодаря социальным факторам. Скромная или даже черствая должность может постепенно поднять престиж и даже закончиться наверху иерархии. Chancellor («канцлер»), заимствованное из французского и, в свою очередь, от позднелатинского cancellarius, («пристав»), который размещался в суде. В Восточной Империи этот служащий продвинулся до секретаря или нотариуса, а затем выполнял судебные функции. Эдуард Исповедник ввел этот вид службы в Англии, и его значение только возросло во времена правления Нормандских королей. Министры также поднялись до своего нынешнего высокого положения от своих скромных должностей: латинское слово minister («министр»), образованный от minus («менее»), означало «служитель, слуга».

В результате движения вверх и вниз по социальной шкале одно и то же слово может появиться в двух разных точках в определенной иерархии. Marshall («маршал»), термин из старо-германского, составленный из слов «лошадь» (mare) и «слуга» (servant), является званием нескольких высокопоставленных офицеров и функционеров в Англии, но во французской армии есть два вида «маршалов»: marechal («фельдмаршал»), и marechal des logis («сержант»). Подобное сходство иногда встречается в значениях одного и того же слова в различных языках, как, например, в английском knight («рыцарь») в сравнении с немецким Knecht («служащий»).

Особая группа мелиоративных и уничижительных событий, которые влияют на значение так называемых «средних терминов»: слов, которые по своей сути нейтральны и которые приобретают благоприятное или неблагоприятное значение в зависимости от контекста. Иногда бывает, что такие слова или их производные становятся фиксированными, либо в положительном, либо в отрицательном значении. Слово fortune («фортуна, удача»), является таким усредненным термином, так как оно может иметь отрицательный или положительный оттенок значения; тем не менее это же слово имеет исключительно положительное значение в прилагательном fortunate «удачливый», а также в метонимическом смысле в значении «богатство, достаток». Luck («удача»), хотя и имеет амбивалентное значение, подразумевает «счастливый случай», когда не существует никакого противоположного значения, а прилагательное lucky имеет только положительное значение.

От слова fate («судьба»), термина, имеющего пессимистический оттенок, образовались два прилагательных fatal («фатальный»), имеющий почти полностью негативное значение, а также fateful («пророческий»), который является более уклончивым по своей семантике.

Сравнительное изучение развития таких слов и выражений в различных языках может пролить свет на психологию человека. С точки зрения масштабов проводимых исследований эти проблемы лучше всего решать в виде серии международных исследовательских проектов. Результаты подобных запросов будут иметь большое значение не только для лингвистики, но и для психологии, для культурной антропологии и различных других дисциплин.

\section{ЛИТЕРАТУРА}

1. Andrew Kehler, Laura Kertz, Hannah Rohde, Jeffrey L. Elman; Coherence and Coreference Revisited, Journal of Semantics, Volume 25, Issue 1, 1 February 2008, Pages 1-44, https://doi.org/10.1093/jos/ffm018

2. Noortje JVenhuizen, Johan Bos, Petra Hendriks, Harm Brouwer; Discourse Semantics with Information Structure, Journal of Semantics, Volume 35, Issue 1, 21 February 2018, Pages 127-169, https://doi.org/10.1093/jos/ffx017

3. Беляевская Е.Г. Когнитивные основания изучения семантики слова / Е.Г. Беляевская // Структуры представления знаний в языке. - М.: РАН, 1994. C. $87-110$.

4. Беляевская Е.Г. Семантическая структура слова в номинативном и коммуникативном аспектах. Дис. Д - ра филол.наук / Е.Г. Беляевская. - М., 1992. - 401 с.

5. Блэк М. Метафора: Пер. с англ. / М. Блэк // Теория метафоры / Общ. ред. Н.Д. Арутюновой и М.А. Журинской. - М.: Прогресс, 1990. - С. 153 - 172.

6. Кубрякова Е.С. Введение. Проблемы представления знаний в языке / Е.С. Кубрякова // Структуры представления знаний в языке. - М.: ИНИОН РАН, 1994. - C. 5-32. 
7. Кубрякова Е.С. Начальные этапы становления когнитивизма: лингвистика - психология - когнитивная наука / Е.С. Кубрякова // Вопросы языкознания. № 4. 1994. - C. $34-47$.

8. Кубрякова Е.С. Проблемы представления знаний в современной науке и роль лингвистики в решении этих проблем / Е.С. Кубрякова // Язык и структуры представления знаний. - М.: ИНИОН РАН, 1992. - С. 4 - 39.

9. Кунин А.В. Курс фразеологии современного английского языка / А.В. Кунин. - М.: Высшая школа, 1996. - 382 с.

10. Fodor J.F.. Concepts: Where Cognitive Science Went Wrong // Oxford: Oxford University Press, 1998. 192 p.

11. Jerrold Katz. Sense, Reference, and Philosophy // 0xford:, 2004, pp. 123-224.

12. Manfred Bierwisch. Syntax, Semantik und Lexikon // Berlin: Akademie-Verlag, 1988. pp. 134-254.

с Алешкевич Сергей Сергеевич (aleshkevichss@mail.ru)

Журнал «Современная наука: актуальные проблемы теории и практики»

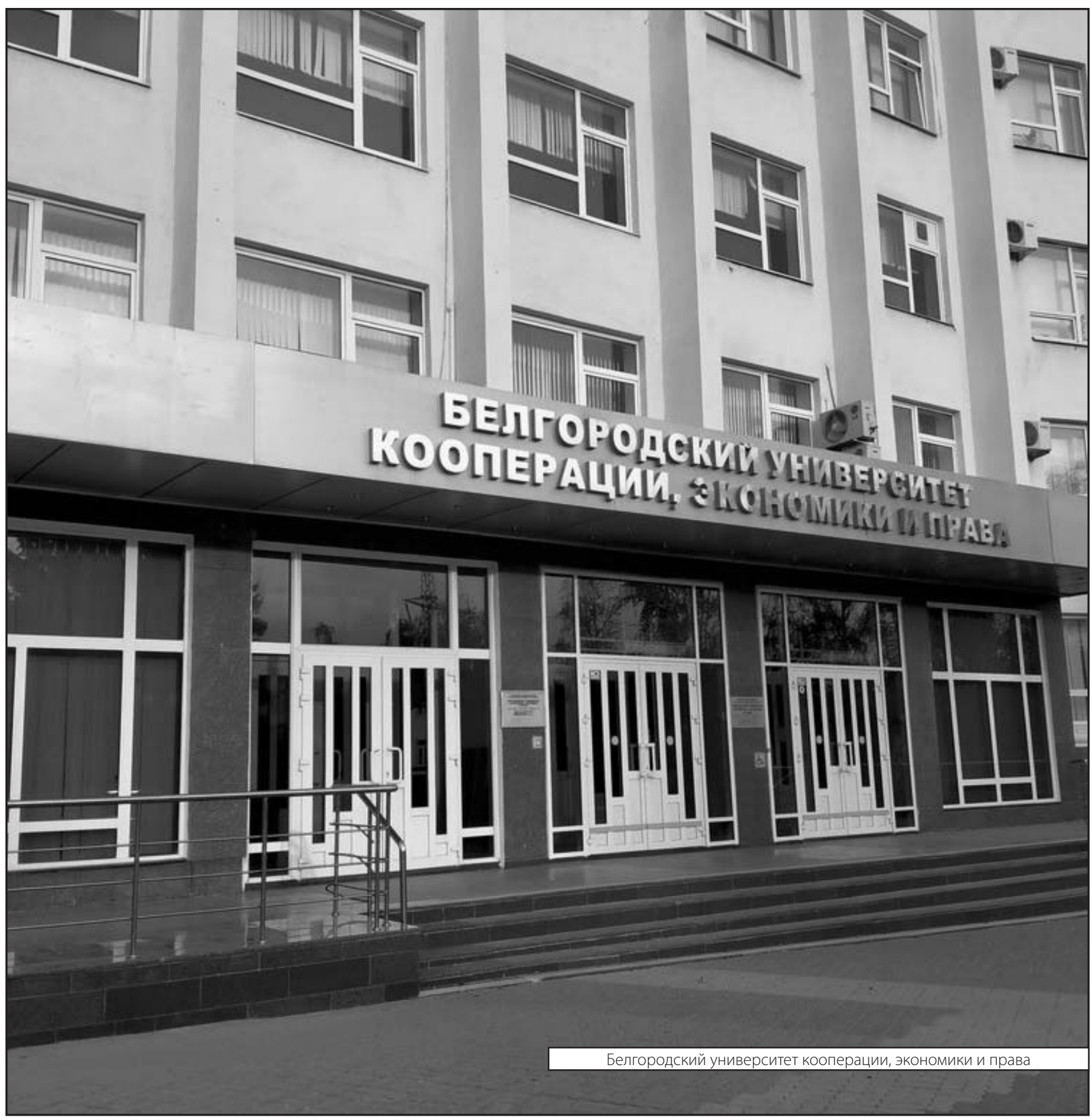

